\title{
A modified way of producing humic acid from composted pineapple leaves
}

\begin{abstract}
Purification of humic acid (HA) is time-consuming (takes between 2 to 7 days). A study was conducted to investigate whether HA produced from composted pineapple leaves could be purified within a day through washing with distilled water. Standard procedures were used to produce $0.1, \mathrm{M} \mathrm{KOH}$ and pineapple leaves compost. The $\mathrm{KOH}$ was used to extract HA in the compost using standard methods with some modifications. The HA was purified by suspending it in $100 \mathrm{ml}$ distilled water, equilibrated for 1 hour, centrifuged for 15 minutes, supernatant decanted, filtered through glass wool and the liquor analyzed for $\mathrm{K}, \mathrm{Ca}, \mathrm{Mg}, \mathrm{Na}$, $\mathrm{Zn}, \mathrm{Mn}$, and $\mathrm{Cu}$ using an atomic absorption spectrophotometer (AAS). This procedure was repeated four times after which the washed HA was oven dried at $30^{\circ} \mathrm{C}$ to a constant weight. Washing HA for four consecutive times within a day was able to reduce the ash content of the HA to $0.1 \%$, a value less than the generally accepted value of less than $1 \%$. This observation was attributed to the remarkable decrease in $\mathrm{K}, \mathrm{Ca}, \mathrm{Mg}, \mathrm{Na}, \mathrm{Zn}, \mathrm{Mn}$, and $\mathrm{Cu}$ with washing. This finding can help in facilitating the production of K-rich humate (organically based fertilizer) from composted pineapple residues in a relatively short time since the HA can be purified within a day for its reconstitution to produce K-humate $(38 \% \mathrm{~K})$ instead of the conventional method that takes between 2 to 7 days. (C) 2004 by The Haworth Press, Inc. All rights reserved.
\end{abstract}

Keyword: Ash; Compost; Humic acid; Pineapple leaves 